\title{
MFS transportome of the human pathogenic yeast Candida albicans
}

\author{
Manisha Gaur ${ }^{1}$, Nidhi Puri², Raman Manoharlal2 ${ }^{2}$ Versha Rai², \\ Gauranga Mukhopadhayay ${ }^{1}$, Devapriya Choudhury*3,4 and \\ Rajendra Prasad*2
}

\begin{abstract}
Address: ${ }^{1}$ Special Centre for Molecular Medicine, Jawaharlal Nehru University, New Delhi, India, ${ }^{2}$ School of Life Sciences, Jawaharlal Nehru University, New Delhi, India, ${ }^{3}$ School of Biotechnology, Jawaharlal Nehru University, New Delhi, India and ${ }^{4}$ School of Information Technology, Jawaharlal Nehru University, New Delhi, India

Email: Manisha Gaur - manisha1310@rediffmail.com; Nidhi Puri - nidhi_puri@rediffmail.com;

Raman Manoharlal - ramanbiotech@gmail.com; Versha Rai - versharai@yahoo.com; Gauranga Mukhopadhayay - gm2300@mail.jnu.ac.in; Devapriya Choudhury* - devach@mail.jnu.ac.in; Rajendra Prasad* - rp47@mail.jnu.ac.in

* Corresponding authors
\end{abstract}

Published: 3 December 2008

BMC Genomics 2008, 9:579 doi:10.1/86/147|-2164-9-579
Received: 17 July 2008

Accepted: 3 December 2008

This article is available from: http://www.biomedcentral.com/I47I-2/64/9/579

(C) 2008 Gaur et al; licensee BioMed Central Ltd.

This is an Open Access article distributed under the terms of the Creative Commons Attribution License (http://creativecommons.org/licenses/by/2.0), which permits unrestricted use, distribution, and reproduction in any medium, provided the original work is properly cited.

\begin{abstract}
Background: The major facilitator superfamily (MFS) is one of the two largest superfamilies of membrane transporters present ubiquitously in bacteria, archaea, and eukarya and includes members that function as uniporters, symporters or antiporters. We report here the complete transportome of MFS proteins of a human pathogenic yeast Candida albicans.

Results: Computational analysis of $C$. albicans genome enabled us to identify 95 potential MFS proteins which clustered into 17 families using Saier's Transport Commission (TC) system. Among these SP, DHAI, DHA2 and ACS represented major families consisting of 22, 22, 9 and 16 members, respectively. Family designations in C. albicans were validated by subjecting Saccharomyces cerevisiae genome to TC system. Based on the published available genomics/proteomics data, 87 of the putative MFS genes of $C$. albicans were found to express either at mRNA or protein levels. We checked the expression of the remaining 8 genes by using RT-PCR and observed that they are not expressed under basal growth conditions implying that either these 8 genes are expressed under specific growth conditions or they may be candidates for pseudogenes.
\end{abstract}

Conclusion: The in silico characterisation of MFS transporters in Candida albicans genome revealed a large complement of MFS transporters with most of them showing expression. Considering the clinical relevance of $C$. albicans and role of MFS members in antifungal resistance and nutrient transport, this analysis would pave way for identifying their physiological relevance.

\section{Background}

Current evidence suggests that Candida albicans acquires azole resistance by employing multiple mechanisms that include (a) alterations in the azole-target protein Erg11p (b) upregulation of the ERG11 gene [1-4] as well as (c) failure of drug accumulation mediated by efflux pumps.
Most commonly, genes encoding drug efflux pumps belonging to ATP binding cassette (ABC) and Major facilitator (MFS) superfamilies of proteins are overexpressed in azole resistant Candida isolates [5-9]. ABC family permeases are in general multicomponent primary active transporters, capable of transporting both small mole- 
cules and macromolecules which is coupled to ATP hydrolysis while the MFS transporters are single-polypeptide secondary carriers capable only of transporting small solutes in response to chemiosmotic ion gradients. We have earlier annotated and classified $\mathrm{ABC}$ transporters in C. albicans [10], however, clinically relevant MFS superfamily in C. albicans largely remains uncharacterized.

MFS superfamily is ubiquitously present in all kingdoms of life and includes members of direct medical and pharmaceutical significance. They are involved in the symport, antiport or uniport of various substrates $[11,12]$ and are known to exhibit specificity for sugars, polyols, drugs, neurotransmitters, Krebs cycle metabolites, phosphorylated glycolytic intermediates, amino acids, peptides, osmolites, siderophores (efflux), iron-siderophores (uptake), nucleosides, organic and inorganic anions, etc $[11,12]$. Most MFS proteins vary between 400 and 600 amino acid residues in length and possess either 12 or 14 putative transmembrane segments (TMS). The MFS superfamily consists of 61 families according to the Transport Commission (TC) system given by Saier and group http:/ /www.tcdb.org/. TC is a comprehensive classification system for membrane transport proteins and is analogous to the Enzyme Commission (EC) system, except that it incorporates both functional and phylogenetic information [13-15]. This system allocates five digits to each phylogenetic cluster of transporters. The first two digits ("class" and "subclass") identify the transport mode and energy-coupling mechanism. The third digit characterizes phylogenetic "families" or "superfamilies." The fourth digit identifies phylogenetic "subfamilies." The fifth digit ("clusters") corresponds to the substrate specificity, as presumed by experimental data or stringent sequence identity [13]. In TC, the designation 2.A.1 represents MFS and the next digit denotes the family, for instance, 2.A.1.1 represents sugar transporters and so on. Any two transport systems in the same subfamily of a transporter family that transport the same substrate(s) are given the same TC number, regardless of whether they are orthologues or paralogues.

Till date only a few MFS transporters namely MDR1, FLU1, NAG3, NAG4, JEN1, ARN1 and NGT1 [16-22], have been identified and characterized in C. albicans. Additionally, over 20 hexose transporters and glucose sensors are known to exist in C. albicans that reflect the varied niches in which this pathogen thrives [23]. However, very limited knowledge about other MFS transporters is available in C. albicans. Out of all the known MFS in C. albicans $M D R 1$, its alleles and FLU1 are shown to be the only drug efflux pumps transporters. MDR1 was initially identified as a gene, which conferred resistance to the tubulin binding agent benomyl and tetrahydrofolate reductase inhibitor methotrexate $[24,25]$. MDR1 expression in S. cerevisiae confers resistance to several unrelated drugs and its overexpression has been linked to azole resistance in C. albicans. The expression of MDR1 in C. albicans cells is enhanced by benomyl, methotrexate and several other unrelated drugs, and is found to be more pronounced in some of the azole resistant clinical isolates [26,27]. Keeping in view, the relevance of the MFS multidrug transporters in general and in multidrug resistance (MDR) in particular, in the present study, we have examined MFS superfamily of proteins in C. albicans. Although, earlier annotation of the previous Candida genome assembly (version 19) predicted 71 MFS genes, no systematic classification was given [28]. To address this question, we have applied a comprehensive bioinformatics approach to identify and annotate all MFS transporter genes in the Candida genome from assembly version 21 and systematically searched for evidence of their expression. It is hoped that these findings will provide the scientific community with the necessary framework needed for the functional characterization of the MFS proteins and a better understanding of this medically and pharmaceutically significant superfamily.

\section{Results \\ Identification and sequence-based functional grouping of C. albicans putative MFS genes}

To identify gene loci encoding MFS proteins, multiple TBLASTN searches were performed on assembly (version 21) of the C. albicans genome http://www.candidagen ome.org using well known MFS proteins as queries. The ORFs thus identified were subjected to domain analysis followed by sequence-based functional grouping, resulting in clustering of putative Candida proteins into various MFS families as described by Saier's TC system. Using this strategy, we identified a total of 95 loci of putative MFS genes in the Candida genome containing the domains characteristic of MFS proteins and were found to be either 12 or 14 transmembrane spanners (Figure 1). By using TC system, all the putative MFS identified were assigned to 17 TC families (Additional file 1). The family assignment obtained by this approach was validated by applying the same strategy to $S$. cerevisiae MFS transportome (data not shown). S. cerevisiae homologues of $C$. albicans MFS proteins were found to take up the same TC cluster thereby addressing the evolutionary relationship between the two yeasts. A summary of the previously known Candida genes together with the new genes is presented in Additional file 1, where, TC family, CGD ORF, gene, alias, TCDB homolog and expression confirmation are listed. In addition, the closest $S$. cerevisiae member within the family is also presented in Additional file 1.

\section{The Sugar Porter (SP) Family (TC \# 2.A.I.I)}

The SP family is widespread and have members from all of the major groups of living organisms: bacteria, archaea, 


\section{A. 12 membrane spanning}

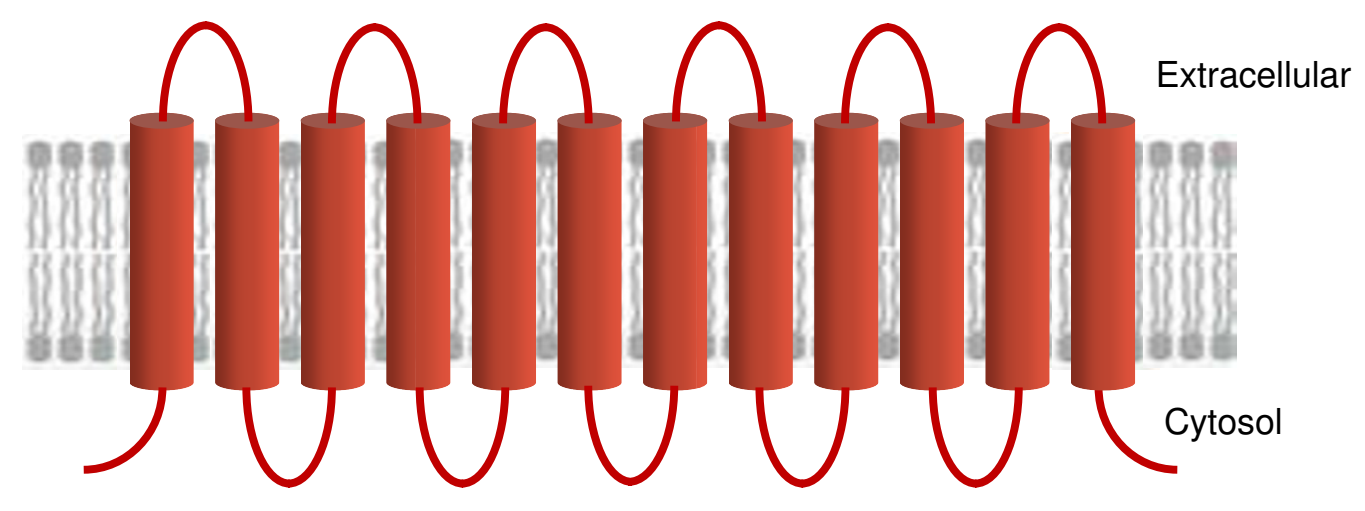

B. 14 membrane spanning

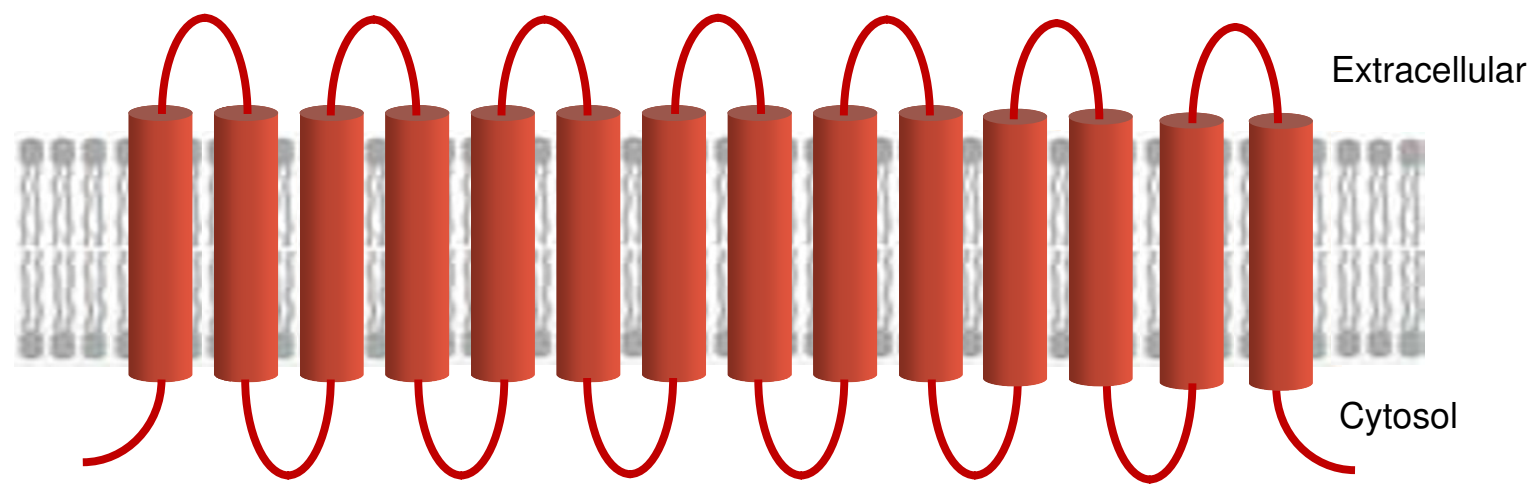

Figure I

Predicted topology of putative MFS proteins of C. albicans. The topology of the putative MFS proteins was predicted using TMHMM program http://www.cbs.dtu.dk/services/TMHMM/. The transmembrane domains were found to be either 12 or 14 transmembrane spanners.

eukaryotic protists, fungi, animals and plants [11]. It forms one of the largest families with 22 members in $C$. albicans. We have previously characterized HGT1 [29] and many studies since then have also reported other SP members namely HGT2-HGT20 [23,30]. Apart from identifying HGT1-HGT20, in the present study, we have also identified two previously unidentified members, namely MAL31 (orf19.3981) and orf19.4923 (Additional file 1) both having homologues in S. cerevisiae, MAL31 and YFL040W, respectively. Further, based on the homology, the 22 SP members show significant similarity with various sugars, namely arabinose, quinate, myoinositol, maltose, fructose, glycerol, monosaccharide, glucose, hexoseand xylose (Additional file 1).
The Drug: $\mathrm{H}^{+}$Antiporter-I (DHAI) Family (TC \# 2.A. I.2)

DHA1 family like the SP is widely distributed and the members include both drug-specific and MDR efflux pumps. Like SP it also forms one of the largest families having 22 members in Candida (Additional file 1). MDR1 gene in C. albicans is one of the best characterized members, originally known to confer resistance to benomyl and methotrexate $[19,20,24,25]$. Subsequent studies indicated that MDR1 also encodes resistance to cycloheximide, benztriazoles, 4-nitroquinolone- $N$-oxide and sulfometuron methyl [24,31]. Disruption of the MDR1 gene reduced the virulence of C. albicans [26]. Other characterized members of this family include FLU1, NAG3 and NAG4. Disruption of FLU1 in C. albicans hyper-sus- 
ceptibility to mycophenolic acid thus suggesting that it could be a preferred substrate for the transporter [17]. On the other hand, NAG3 (TMP1) and NAG4 (TMP2) show susceptibility to a number of unrelated compounds such as cycloheximide, 4-nitroquinoline- $N$-oxide and 1,10phenanthroline and are upregulated in response to these drugs, suggesting that they function as multiple drug efflux pumps [21]. Apart from MDR1, which is known as a clinically relevant efflux pump protein, none of the other characterized members have been directly linked to MDR of C. albicans.

The Drug: $\mathrm{H}^{+}$Antiporter-2 (DHA2) Family (TC \# 2.A. I.3) The DHA2 family of drug: $\mathrm{H}^{+}$antiporters with 14 predicted transmembrane-spanning segments, consists of nine members in C. albicans which show significant similarity to transporters, namely aminotriazole, 4-nitroquinoline$\mathrm{N}$-oxide, $\mathrm{Me}^{2+}$-tetracycline antiporter, vacuolar basic amino acid (Arg, Lys, His) transporter and metal:tetracycline/oxytetracycline efflux pump (Additional file 1). In C. albicans no member of this family has yet been characterized whereas in S. cerevisiae two DHA2 proteins, SGE1 and ATR1 are well studied. ATR1 has been shown to confer resistance to the structurally unrelated compounds aminotriazole and 4-nitroquinolone- $\mathrm{N}$-oxide and expression of ATR1 is inducible by the former but not the latter [32,33]. SGE1 appears to confer resistance to crystal violet [34] and ethidium bromide [35,36].

\section{The Fucose: $\mathrm{H}^{+}$Symporter (FHS) Family (TC \# 2.A. I.7)}

FHS is a small family with two ORFs identified in Candida namely: orf19.4090 and orf19.7490 (Additional file 1). They are homologous to S. cerevisiae BSC6, which encodes a protein of unknown function exhibiting genomic organization compatible with a translational read throughdependent mode of expression [37].

The Phosphate: $\mathrm{H}^{+}$Symporter (PHS) Family (TC\# 2.A. I.9) PHS family is unusual in that it has representatives only in yeast, fungi and plants but none in bacteria, animals and other eukaryotes [11]. The occurrence of distant homologues in both the plant and fungal kingdoms suggests that they possess isoforms that diverged from each other well before plants diverged from fungi [11]. Two well characterized members of the PHS family are the Pho84 inorganic phosphate transporter of S. cerevisiae [38] and the GvPT phosphate transporter of Glomus versiforme [39]. In this study, we have identified five ORFs belonging to PHS family in C. albicans with homology to phosphate: $\mathrm{H}^{+}$symporters (Additional file 1). However, none of the members identified in Candida has yet been characterized.

\section{The Oxalate: Formate Antiporter (OFA) Family (TC \#} 2.A.I.II)

OFA family members are widely distributed in nature, being present in the bacterial, archaeal and eukaryotic kingdoms [11]. In C. albicans, our searches revealed two members (Additional file 1). OxlT, the oxalate:formate antiporter from Oxalobacter formigenes, is the hallmark protein and provides the basis for naming the OFA family $[40,41]$. This protein has been purified, reconstituted in an artificial membrane system as well as structurally and functionally characterized $[42,43]$.

\section{The Sialate: $\mathrm{H}^{+}$Symporter (SHS) Family (TC \# 2.A. I.I2)}

SHS family, like the PHS family, is very small with only two members namely JEN1 and JEN2, identified in the present as well as a previous study [44]. JEN1 has been described as the first monocarboxylate transporter of $C$. albicans showing loss of all measurable lactate permease activity upon its disruption. Further, lactate uptake by JEN1 was competitively inhibited by pyruvic and propionic acids while acetic acid behaved as a non-competitive substrate [22].

\section{The Monocarboxylate Porter (MCP) Family (TC \#}

2.A.I.I3)

MCP family is exclusively present in yeasts and animals. In mammals, these permeases are known to transport monocarboxylates, namely pyruvate, lactate and mevalonate with inwardly-directed polarity and presumably function as proton symporter [11] while it is reported that the yeast monocarboxylate transporter proteins perform functions other than their mammalian counterparts [45]. This family has six members identified in Candida.

The Anion: Cation Symporter (ACS) Family (TC \# 2.A. I.I4) ACS is a relatively large family having representation in bacteria, yeasts and animals comprising mainly of symporters that are known to accumulate their substrates in symport with either $\mathrm{Na}^{+}$or $\mathrm{H}^{+}$, depending on the system. They may transport either inorganic (e.g. phosphate) or organic anions (e.g. glucarate, hexuronate, tartrate, allantoate or 4-hydroxylphenyl acetate) [11]. In Candida, we have identified 16 members showing significant similarity to transporters having prefered substrates, namely tartrate, allantoate, nicotinate, biotin and pantothenate (Additional file 1).

\section{The Aromatic Acid: $\mathrm{H}^{+}$Symporter (AAHS) Family (TC \# 2.A.I.15)}

The members of AAHS family occur exclusively in gramnegative bacteria where they are known to transport a variety of aromatic acids like benzoate, 4-hydroxybenzoate, 3hydroxyphenylpropionate, 2,4-dichlorophenoxyacetate as well as niacin and cis, cis-muconate [11]. In Candida, a single member of AAHS family has been identified, namely orf19.6952 showing significant similarity to putative niacin uptake porter (Additional file 1). This family has no representation in S. cerevisiae and thus unique to Candida. 
The Siderophore-Iron Transporter Family (TC \# 2.A. I. I6) All the known members of this family are from yeast species. In C. albicans this family is represented by a single protein known as siderophore transporter, SIT1/ARN1 (orf19.2179) which is required in ferrichrome-iron uptake. Previous reports suggest that deletion of ARN1 leads to reduced ability of $C$. albicans to use iron bound to the hydroxamate-type siderophore ferrichrome and upon deletion of the two high-affinity iron permease C. albicans genes (FTR1 and FTR2), the activity was completely abolished $[18,46]$. According to another study, siderophore uptake by Sit1p/Arn 1p is required in a specific process of C. albicans infection, namely epithelial invasion and penetration, while in the blood or within organs other sources of iron, including heme, may be used [47].

\section{The Organic Cation Transporter (OCT) Family (TC \# 2.A.I.19)}

In C. albicans this family is represented by a single uncharacterized member FGR2 (orf19.7071) showing similarity to organic anion: dicarboxylate transporter. These proteins are known to transport organic cations and/or anions and catalyze uptake of cationic drugs such as tetramethyl ammonium, cimetidine, procainamide, quinidine and some endogenous metabolites such as $\mathrm{N}$ methyl-nicotinamide [48-51].

\section{The Vesicular Neurotransmitter Transporter (VNT) Family} (TC \# 2.A. I.22)

These proteins are more closely related to SP family than to other MFS families. The better characterized members of the VNT family are synaptic vesicle proteins from mammals, the electric eel and insects [52-55]. In C. albicans this family is represented by a single member orf 19.6578 with significant similarity to dopamine transporter.

\section{The Peptide-Acetyl-Coenzyme A (PAT) Transporter Family (TC \# 2.A. I.25)}

Members of the PAT family are present across bacteria, yeast and animals [11]. Amongst the well characterized proteins of this family include acetyl-CoA transporter localized in the endoplasmic reticulum and Golgi membranes of humans [56]. AmpG protein of E. coli belonging to PAT family, brings into the cell peptides, including cell wall degradative peptides and glycopeptides, to act as inducers of $\beta$-lactamase synthesis [57]. The acetyl-CoA transporter is expected to function by acetyl-CoA:CoA antiport while the AmpG protein is most likely energized by substrate: $\mathrm{H}^{+}$symport. In C. albicans this family is represented by a single member orf19.3782 with significant homology to acetyl-CoA:CoA antiporter.

\section{The L-Amino Acid Transporter-3 (LAT3) Family (TC \# 2.A. I.44) (also called the SLC43 family)}

LAT3 transports neutral amino acids such as L-leucine, Lisoleucine, L-valine and L-phenylalanine by a $\mathrm{Na}^{+}$-inde- pendent, electroneutral, facilitated diffusion process and also transports amino acid alcohols. In C. albicans, this family is represented by two ORFs: orf19.6654 and orf19.6316.

\section{The Proton Coupled Folate Transporter/Heme Carrier Protein (PCFTIHCP) Family (TC \# 2.A. I.50)}

In $C$. albicans, this family is represented by a single member orf19.6976 showing homology to high-affinity folate transporter. PCFT from human has been shown to act both as an intestinal proton-coupled high-affinity folate transporter and as an intestinal heme transporter which mediates heme uptake from the gut lumen into duodenal epithelial cells. The iron is then released from heme and may be transported into the bloodstream $[58,59]$.

\section{The N-Acetylglucosamine Transporter Family (TC \# 2.A.I.58)}

NGT1 from C. albicans represents the first eukaryotic $N$ acetylglucosamine (GlcNAc) transporter and is the only known member of this family. It is required for efficient GlcNAc uptake and for inducing hyphae development at low GlcNAc concentrations [16]. High concentrations of GlcNAc could bypass the need for NGT1 to induce hyphae, indicating that elevated intracellular levels of GlcNAc induce hyphal formation. Expression of NGT1 in $S$. cerevisiae promoted GlcNAc uptake, indicating that NGT1 acts directly as a GlcNAc transporter [16]. No homologue of NGT1 was detected in S.cerevisiae.

\section{Most of the identified members of MFS superfamily are expressed}

To assess which of the identified Candida MFS transporter genes are transcribed or translated, we analyzed all 95 MFS transporter loci by extensive mining of the data available from the genome or proteome-wide studies in C. albicans. Using this approach, we found that out of the 95 ORFs, 87 were shown to express either at mRNA or protein level under different experimental conditions (see Additional file 1). To validate the expression of the remaining 8 putative MFS genes (orf19.1582, orf19.7336, orf19.4090, orf19.6180, orf19.1424, orf19.6520, orf19.6654 and orf19.6976), we employed reverse transcriptase PCR (RT-PCR) approach taking a well characterized C. albicans MFS transporter, MDR1 as a positive control. The primers utilized for expression analysis are shown in Table 1. Interestingly, no expression was detected in any of the 8 putative genes tested under the basal condition (Figure 2).

\section{Discussion and conclusion}

In this study, we report the complete transportome of MFS superfamily of $C$. albicans. Computational analysis of the C. albicans genome assembly (version 21) from CGD enabled us to identify 95 potential MFS permeases. The latter were classified according to both phylogeny and function 
based TC system earlier developed by Saier [13,15]. This approach enabled us to cluster these $95 \mathrm{MFS}$ proteins into 17 distinct families. Indeed each of the predictions must be tested experimentally before final conclusions are reached with reference to the expression and function of the proteins analyzed.

The comparison between C. albicans and S. cerevisiae MFS genes revealed that predominantly most of the families are present in both the organisms (Figure 3A). Notably, there were few families that were present only in C. albi- cans: OFA, AAHS, OCT, VNT, PCFT/HCP and NAG-T (Figure 3B). Interestingly, in OFA family, the S. cerevisiae MFS genes, MHC1 and YMR155W, although orthologues of $C$. albicans orf19.6180 and orf19.1424, respectively, yet do not conform to the same TC family designation as Cand$i d a$, rather these genes were found to be more similar to OxlT of Oxalobacter formigenes, a bacterial oxalate: formate antiporter (Additional file 1). Similar was the case with $C$. albicans orf19.6976, where the S. cerevisiae orthologue, YJL163C, belong to DHA1 family instead of PCFT/HCP family (Additional file 1). It was also observed in the

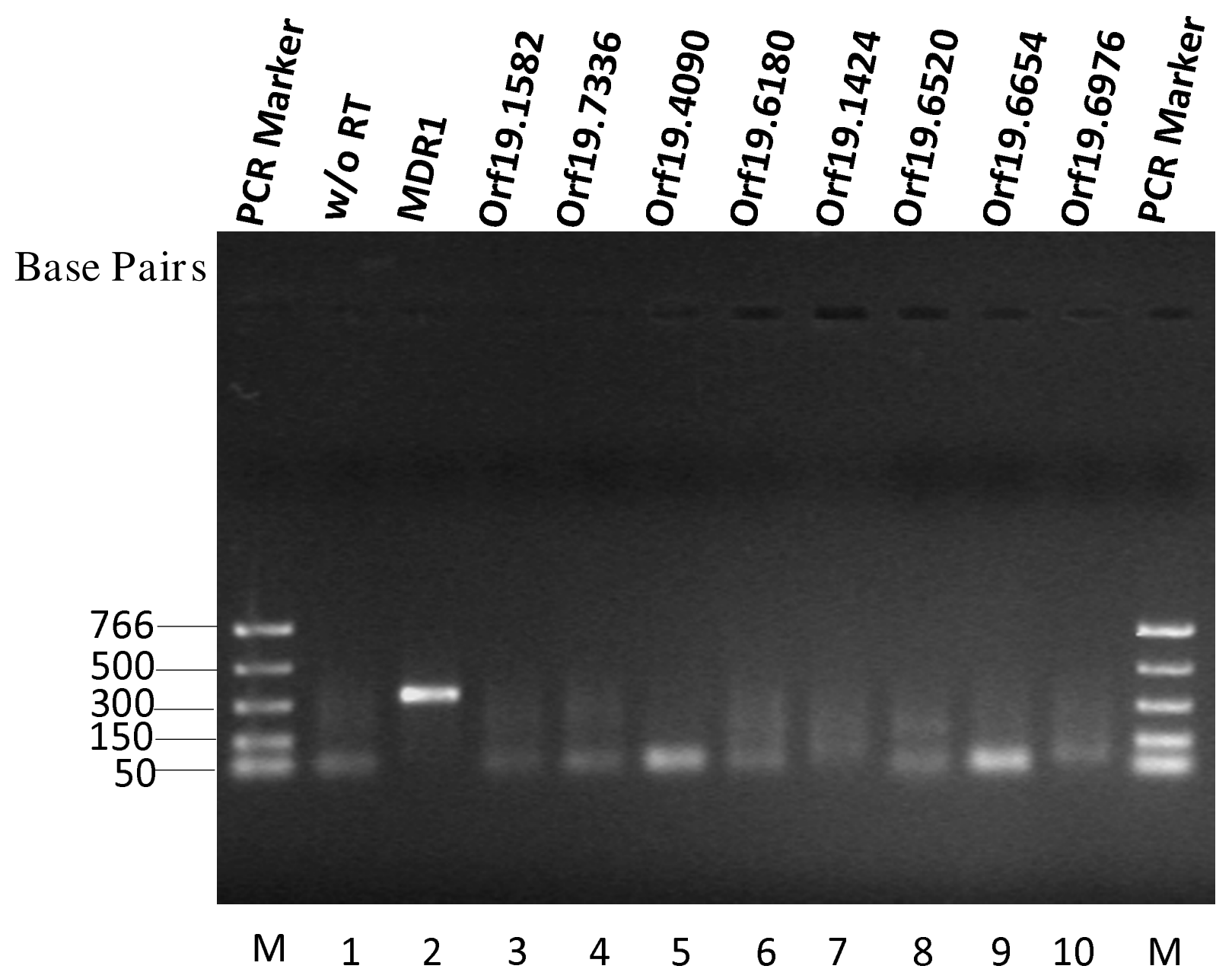

\section{Figure 2}

Expression analysis of putative MFS genes by RT-PCR. The expression of 8 putative MFS genes, which were not validated by the mRNA/protein profiling data mining, was checked by RT-PCR. Purified poly $(A)^{+}$enriched mRNA fractionated from $C$. albicans isolate SC53I4 were amplified by RT-PCR, as described in the Methods. Following electrophoresis through I.2\% agarose gel, the amplified PCR products were visualized by staining with ethidium bromide. Lane M, nucleotide size marker (PCR Marker); lane I, without RT (negative control); lane 2, MDRI (positive control, 330 base pairs); lane 3, orf19.1582; lane 4, orf19.7336; lane 5, orf19.4090; lane 6, orf19.6I80; lane 7, orf19.I424; lane 8, orfl9.6520; lane 9, orf19.6654 and lane 10, orf19.6976. 
Table I: Oligomers used for RT-PCR

\begin{tabular}{|c|c|c|}
\hline Oligomer & Sequence (5'-3') & Expected amplicon length (bp) \\
\hline MDRI-F & CACCGTTATGGAACCAGTTG & 330 \\
\hline MDRI-R & CAGCACCAAACAATGGACCAACCCAATGAG & \\
\hline orfl9.1582-F & GAAACTTTGGTATCCTGGAAC & 380 \\
\hline orf।9.1582-R & CAACAAAATGGCAAAACCACC & \\
\hline orfl9.7336-F & CGCTTTCCAACCATCAATGG & 464 \\
\hline orfl9.7336-R & CAGTCATTGAAGAAGCAGAAG & \\
\hline orfl 9.4090-F & GAGAAGGGGCGTTTTTATTG & 301 \\
\hline orfl9.4090-R & CACAATGAAAACCGGTAACAC & \\
\hline orfl9.6180-F & GGTTGTTGTTAGGTGTGTTG & 394 \\
\hline orf। 9.6 I80-R & CAAAATCTCGTAAACCCACG & \\
\hline orfl9.1424-F & CAGTACAAACATTACAAGCCC & 476 \\
\hline orf|9.|424-R & CACCACAAATGTCATACCAC & \\
\hline orfl 9.6520-F & GCCTTACATCCACGCAATTTG & 339 \\
\hline orf|9.6520-R & CTAAAATCTAACCTCTTGGCGC & \\
\hline orf| 9.6654-F & CTATTGGGTTGTTGGGTTTG & 286 \\
\hline orf|9.6654-R & GTCGAGCCTCCAATAATACCTG & \\
\hline orfl9.6976-F & CTCCCCCTTGGTTATATTAAC & 603 \\
\hline orfl 9.6976-R & CCAGGCCAACCATTTTTCAAAG & \\
\hline
\end{tabular}

AAHS family, Candida genes are more closely related to gram-negative bacteria (Additional file 1) as compared to $S$. cerevisiae which probably explains the absence of homologues of this family in $S$. cerevisiae. On a similar pattern, the MFS genes of $C$. albicans belonging to OCT and VNT families are closely related to animals and no significant homologies were detected in S. cerevisiae genome. The NAG-T family also did not find any representation in $S$. cerevisiae genome. Taken together, these findings point out that probably these genes had diverged during the course of evolution. Interestingly, vacuolar basic amino acid (V-BAAT) family present in $S$. cerevisiae has no representation in C. albicans (Figure 3B). Although the C. albicans ORFs, orf19.1308 and orf19.7554 show significant homology to $S$. cerevisiae V-BAAT family members, VBA1 and $V B A 2$, respectively, they belong to DHA2 family supporting the fact that V-BAAT family is most similar to the DHA2 family.

Our expression analysis of the published work revealed that out of 95 MFS genes, 87 are expressed under either basal (uninduced) or in different specific experimental conditions (Additional file 1). Most of the genes identified in the present investigation are expressed either at mRNA or protein level thus validating our analysis. The expression of the remaining 8 genes was not detected. This would imply that either these genes are expressed under specific growth condition or that they may be candidate pseudogenes. To dissect the role of each putative member of MFS superfamily, an essential part of the process will now involve construction of multiple knockout mutants, which will enable to unravel their role in drug or nutrient transport.

\section{Methods}

Media chemicals were obtained from HiMedia (Mumbai, India). Luria Bertani broth and agar media was purchased from Difco, BD Biosciences, NJ, USA. Taq DNA polymerase, ultra pure deoxyribonucleotides (dATP, dGTP, dCTP and dTTP) were obtained from New England Biolabs (NEB Inc.), USA. Moloney murine leukemia virus (MMuLV) reverse transcriptases (RT) and RNase inhibitor were obtained from MBI Fermentas. Oligotex mRNA Mini Kit was purchased from Qiagen. Oligonucleotides used were commercially synthesized from Sigma-Aldrich. All Molecular Biology (MB) grade chemicals used in this study were obtained from Sigma Chemical Co. (St. Louis, USA).

\section{Identification of C. albicans MFS transporter genes}

C. albicans genome assembly version 21 http://www.can didagenome.org was searched for MFS genes using well known MFS proteins from Swiss-Prot database http:// www.expasy.ch/sprot as queries in TBLASTN searches [60]. Our initial query dataset had 230 MFS proteins which were used individually to BLAST Candida genome. Out of 230 sequences, 38 were chosen which gave significant E-values and were maximally dissimilar among themselves covering diversity of MFS from plants, fungi and mammals. It should also be noted that although a rather relaxed E-value (0.0001) cut-off was used, the observed E-values between the test sequence and the closest query sequence were much below this threshold indicating that the hits obtained were highly significant. The high-scoring segment pairs (HSPs) returned from TBLASTN searches were checked for duplications using an in-house written Perl script and only those that gave the lowest E-value with one or the other sequences from the 
A.

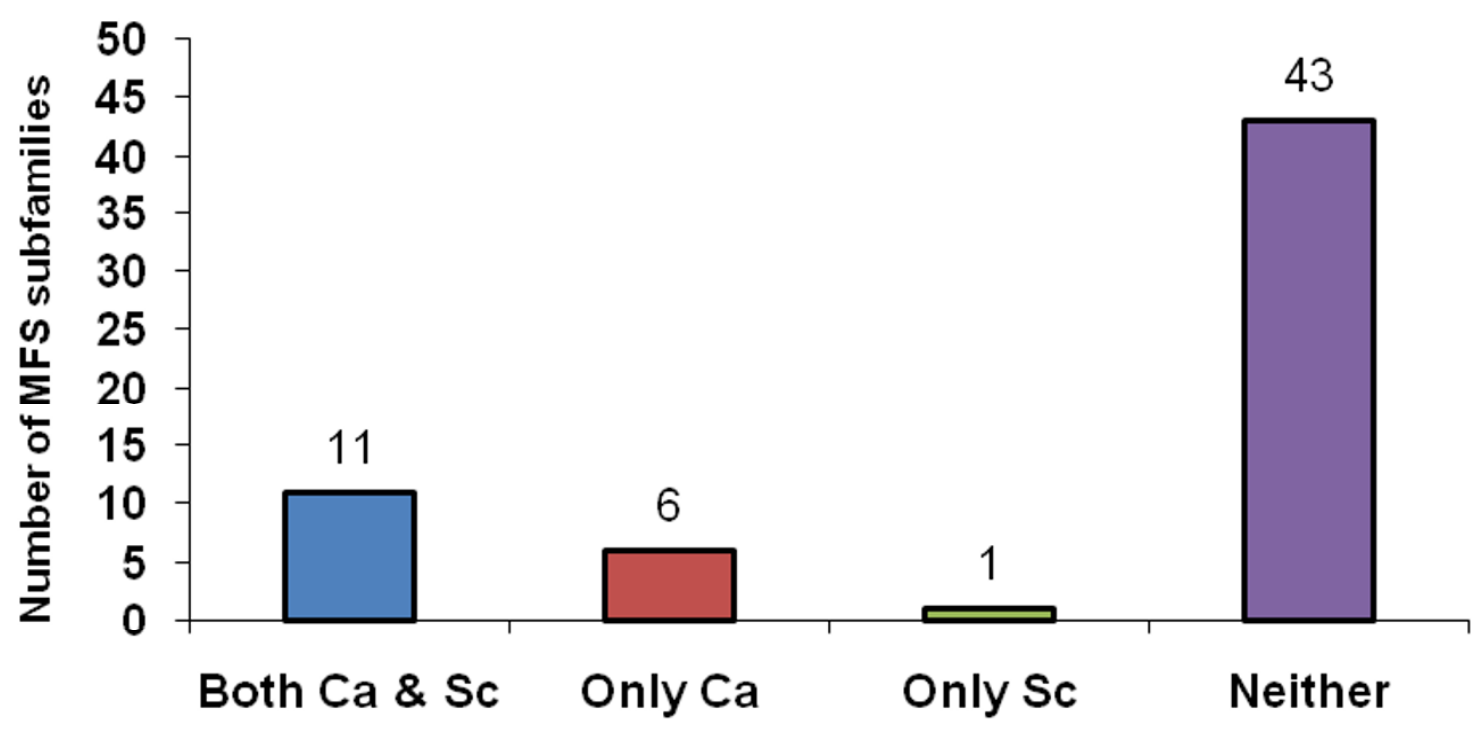

B.

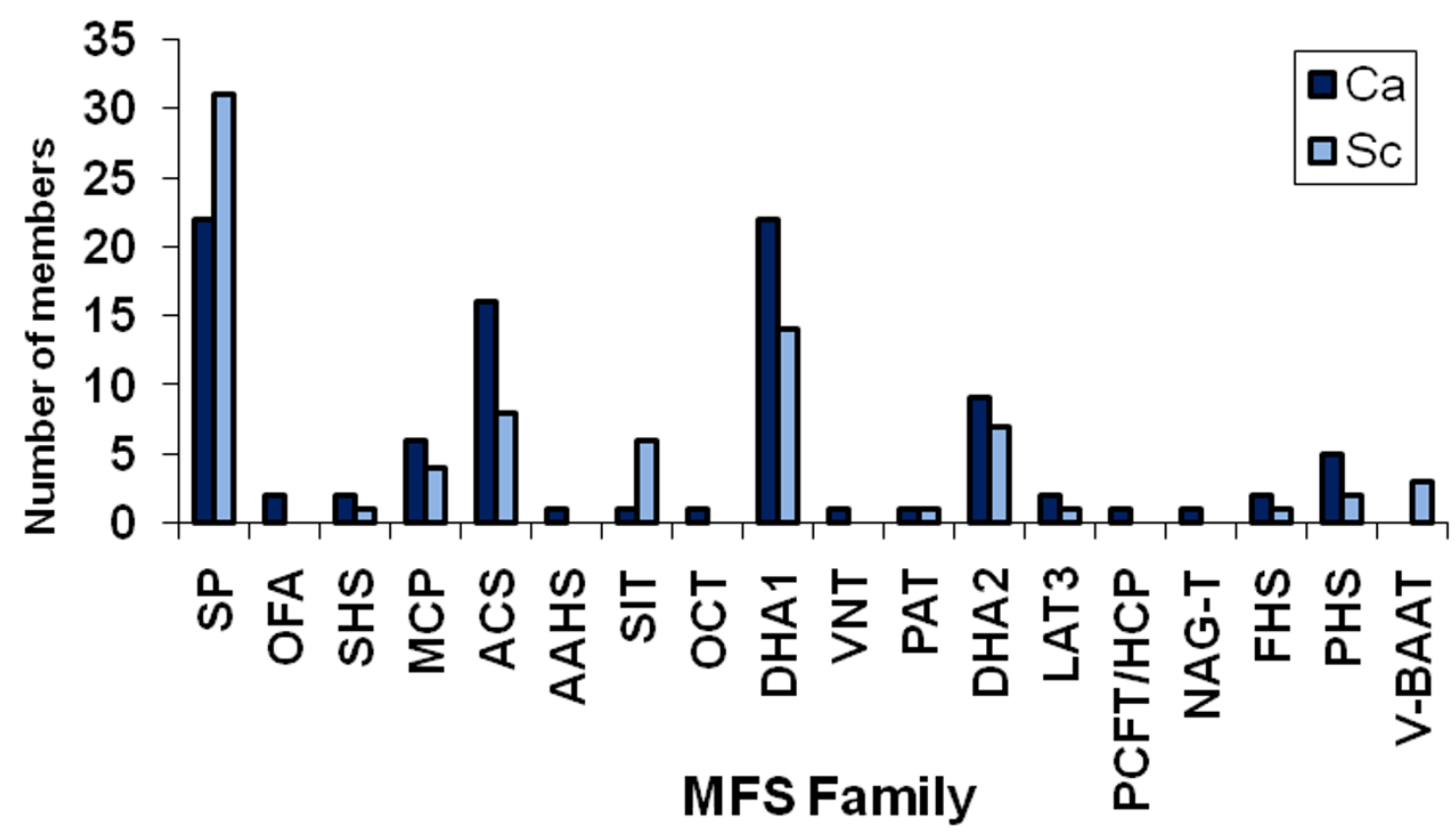

Figure 3

Distribution of MFS families in C. albicans as per transport commission (TC) system and comparison with $S$. cerevisiae. (A) Family designations were according to TC system as mentioned in the Methods. Ca and Sc stand for C. albicans and S. cerevisiae, respectively. Out of $6 \mathrm{I}$ reported MFS families in TC database http://www.tcdb.org/, 17 were identified in $C$. albicans as compared to 12 known in S. cerevisiae. (B) A comparison of MFS families between C. albicans and S. cerevisiae revealed that the members of the same family were almost equal in number in both the yeasts. Interestingly, 6 families that were present in C. albicans had no representation in S. cerevisiae whereas there was only one such family in S. cerevisiae which had no counterpart in C. albicans. 
query set were kept for further analysis. The overlapping HSPs were merged so as to obtain the largest contiguous stretch of nucleotides in the C. albicans genome, which had strong sequence homology with the MFS proteins in the query dataset. Since the test sequences always gave significant hits with a number of query sequences the best individual alignments were merged using overlaps. The availability of multiple TBLASTN matches (on account of the large number of query sequences used) made the merging step relatively easy and unambiguous. It also greatly increased the reliability of identifying a true hit and distinguishing it from false positives. The protein sequences were obtained by a six frame translation of the HSPs, using the tool "transeq" from the EMBOSS package http://www.ebi.ac.uk/emboss/transeq and taking the largest open reading frame (ORF). 95 ORFs identified from $C$. albicans after the initial TBLASTN searches were then pooled with the query dataset of 38 sequences to form a new query dataset and used iteratively for subsequent searches until no new ORFs were obtained. Subsequently, all potential genes were analyzed for MFS domains using the programs ExPASY PROSITE [61], InterPro [62] and Conserved Domain Database at NCBI [63]. Transmembrane domains were predicted using TMHMM http:// www.cbs.dtu.dk/services/TMHMM/.

\section{Sequence-based functional grouping of C. albicans MFS genes}

C. albicans MFS genes, as identified above, were further subjected to sequence-based classification according to TC system which is based on both functional and phylogenetic information $[13,14,64]$. Each putative MFS was individually searched against the TCDB. For this purpose the BLAST server at the transporter database http:// www.tcdb.org was used with the default settings and Evalue cut-off of 1.0 from the given choices of E-values (1000 to 0.0001$)$. It should be noted that here also we chose a rather relaxed E-value cut-off and the potential MFS identified in Candida returned much lower E-values with the MFS sequences in the transporter database. To validate the family designations obtained for $C$. albicans using TC system all the known $S$. cerevisiae MFS proteins were also searched against the TC database using the same method as described for C. albicans.

\section{Phylogenetic relationship with S. cerevisiae}

A systematic search for $S$. cerevisiae homologues of the proteins was done with each $C$. albicans MFS gene by using SGD BLASTP tool http://www.yeastgenome.org/.

\section{Expression analysis of the putative MFS genes}

In order to validate the existence of the putative MFS genes in C. albicans, expression analysis was done by extensive mining of the data available from the previous genome and proteome-wide studies (Additional file 1) as well as experimentally by RT-PCR.

\section{Total RNA isolation}

Total RNA from C. albicans isolate SC5314 was prepared from mid-logarithmically grown phase cells. In a standard preparation, $10 \mathrm{ml}$ of cells, optical density at $600 \mathrm{~nm}$ $\left(\mathrm{OD}_{600}\right)$ of 1.0 , were pelleted and washed with $10 \mathrm{ml}$ of ice-cold $\mathrm{H}_{2} \mathrm{O}$ and spun at $5000 \mathrm{rpm}$. The pellet was resuspended in $1.0 \mathrm{ml}$ of TRI ${ }^{\circledR}$ Reagent (Sigma) and $0.3 \mathrm{ml}$ of ice-cold, acid-washed $0.4-0.6 \mathrm{~mm}$ diameter glass beads (Sigma, St. Louis, MO, USA) were added and vortexed for $5 \mathrm{~min}$. Chloroform ( $0.2 \mathrm{ml})$ without isoamyl alcohol was added and the tubes were shaken vigorously for $15 \mathrm{~s}$. The samples were incubated at room temperature for $15 \mathrm{~min}$, centrifuged at $12,000 \times \mathrm{g}$ for $15 \mathrm{~min}$ at $4^{\circ} \mathrm{C}$. The upper colourless aqueous phase was transferred to a new tube and $0.5 \mathrm{ml}$ of isopropanol was added. The tubes were incubated at room temperature for $10 \mathrm{~min}$, centrifuged at $12,000 \times \mathrm{g}$ for $10 \mathrm{~min}$ and the pellet washed with $75 \%$ ethanol and recentrifuged. The pellet was air dried and resuspended in $100 \mu \mathrm{l}$ of $\mathrm{H}_{2} \mathrm{O}$. All the experiments were done with diethyl pyrocarbonate (DEPC) treated $\mathrm{H}_{2} \mathrm{O}$. DNA free RNA was prepared by treating total RNA with DNase RQ1 (Promega). The $\mathrm{OD}_{260}$ and $\mathrm{OD}_{280}$ were measured and the integrity of the total RNA was visualized by subjecting 2-5 $\mu \mathrm{l}$ of the sample to electrophoresis through a denaturing $1 \%$ agarose $/ 2.2 \mathrm{M}$ formaldehyde gel. The total RNA preparation isolated was stored at $-80^{\circ} \mathrm{C}$ till further use.

\section{Reverse transcription PCR (RT-PCR)}

The nucleotide sequence of the oligonucleotide primers used for the RT-PCR was taken from CGD http:// www.candidagenome.org. Total RNA isolated from SC5314 (as described above) was enriched with poly(A)+ (polyadenylated) mRNA using the Oligotex mRNA Mini Kit protocol (Qiagen) and used subsequently for performing the reverse transcription reaction as described elsewhere [65]. To synthesize cDNA, ca. $0.1 \mu \mathrm{g}$ of poly(A)+ RNA was placed in a $0.5 \mathrm{ml}$ reaction tube with $1 \mu \mathrm{M}$ of oligo $(\mathrm{dT})_{18}$ anchor primer stock and the volume was adjusted to $11 \mu \mathrm{l}$ with DEPC treated water. The mixture was incubated for $10 \mathrm{~min}$ at $70^{\circ} \mathrm{C}$ and chilled on ice for 1 min, after which the remainder of the reaction mixture was added from a master mix to the reaction tube in order for each reaction to contain a $1 \mathrm{mM}$ concentration each of dATP, dCTP, dGTP and dTTP; 40 U of RNase inhibitor in a buffer consisting of $50 \mathrm{mM}$ Tris- $\mathrm{HCl}$ (pH 8.3), $50 \mathrm{mM}$ $\mathrm{KCl}, 4 \mathrm{mM} \mathrm{MgCl}_{2}$ and $10 \mathrm{mM}$ DTT. After brief mixing, the reaction was incubated for $10 \mathrm{~min}$ at $37^{\circ} \mathrm{C}$ followed by addition of $40 \mathrm{U}$ of $\mathrm{M}-\mathrm{MuLV}$ reverse transcriptase. Finally, the reaction was incubated at $37^{\circ} \mathrm{C}$ for $60 \mathrm{~min}$ and then stopped by heating at $70^{\circ} \mathrm{C}$ for $10 \mathrm{~min}$ followed by chilling it on ice for $1 \mathrm{~min}$. The synthesized cDNA was purified from unincorporated dNTPs, oligo $(\mathrm{dT})_{18}$ anchor primer and proteins by using Oligotex mRNA Mini Kit. Amplification of specific mRNA of each gene was performed using corresponding appropriate dilution of cDNA as 
template (generally $1: 4$ ) and $1 \mu \mathrm{M}$ of each specific forward and reverse PCR primer as mentioned in Table 1. (parameters: initial denaturation of $95^{\circ} \mathrm{C}$ for 5 min followed by 35 cycles denaturation at $95^{\circ} \mathrm{C}$ for $15 \mathrm{~s}$, annealing at $55^{\circ} \mathrm{C}$ for $30 \mathrm{~s}$, elongation at $72^{\circ} \mathrm{C}$ for $30 \mathrm{~s}$ and final extension at $72^{\circ} \mathrm{C}$ for $10 \mathrm{~min}$ ). As a positive control, MDR1 specific forward MDR1-F and reverse MDR1-R primer (corresponding to positions 1038-1396 in the MDR1 genomic sequence) was also used. The negative control (without RT) established that the PCR products generated in the RT-PCR were not due to genomic DNA contamination (data not shown). Resulting RT-PCR products were electrophoresed on a $1.2 \%$ agarose gel in $1 \times$ TAE.

\section{Authors' contributions}

MG identified and annotated MFS proteins in C. albicans and wrote the manuscript. NP and VR facilitated the bioinformatics analyses, particularly with respect to accessing and extracting database information and domain identification. RM was responsible for the experimental part. GM took part in the revision of this article. DC contributed expert knowledge and participated in the design and coordination of the study. RP conceived the study and helped to draft the manuscript. All authors read and approved the final manuscript.

\section{Additional material}

\section{Additional file 1}

A summary of C. albicans potential MFS genes listing TC family designation, CGD ORF, gene, alias, TCDB homolog and expression confirmation along with the closest $\mathrm{S}$. cerevisiae member within the TC family. ${ }^{a}$ Saier's Transport Commission (TC). ${ }^{b}$ CGD ORF number http:/ www.candidagenome.org/. ${ }^{\circ}$ TCDB homolog obtained from BLAST searches in the transporter database http://www.tcdb.org. ${ }^{d}$ Systematic search for $\mathrm{S}$. cerevisiae homologues of the proteins was done with each gene by using SGD BLASTP tool http://www.yeastgenome.org/. ${ }^{e}$ Expression Confirmation - M: Microarray, N: Northern Analysis, R: RT-PCR, MS: Mass Spectroscopy. The data has been analysed from the genome/proteome wide studies on C. albicans [16,23,66-71]. Bold, Italics ORFs indicate genes which were experimentally tested by RT-PCR in the present study. ${ }^{*}$ Genes with a strong homolog in fungi but absent from human and murine genomes [28].

Click here for file

[http://www.biomedcentral.com/content/supplementary/14712164-9-579-S1.doc]

\section{Acknowledgements}

The work presented in this paper has been supported in parts to RP by grants from Department of Biotechnology, (DBT/PR4862/BRB/I0/360/ 2004), Council of Scientific and Industrial Research (38(I I 22)/06/EMR-II, 22/3/2006), Department of Science and Technology (SR/SO/BB-12/2004, 5/ 9/2005) and Indo-French Centre for the Promotion of Advanced Research (IFC/A/3403-2/2006). MG and NP acknowledge the University Grants Commission, India and Indian Council for Medical Research, respectively, for the support in the form of junior and senior research fellowships.

\section{References}

I. Mukhopadhyay K, Prasad T, Saini P, Pucadyil TJ, Chattopadhyay A Prasad R: Membrane sphingolipid-ergosterol interactions are important determinants of multidrug resistance in Candida albicans. Antimicrob Agents Chemother 2004, 48: I778- 1787.

2. Pasrija R, Krishnamurthy S, Prasad T, Ernst JF, Prasad R: Squalene epoxidase encoded by ERGI affects morphogenesis and drug susceptibilities of Candida albicans. J Antimicrob Chemother 2005, 55:905-913

3. Prasad T, Saini P, Gaur NA, Vishwakarma RA, Khan LA, Haq QM, Prasad R: Functional analysis of CaIPTI, a sphingolipid biosynthetic gene involved in multidrug resistance and morphogenesis of Candida albicans. Antimicrob Agents Chemother 2005, 49:3442-3452.

4. Prasad R, Gaur NA, Gaur M, Komath SS: Efflux pumps in drug resistance of Candida. Infect Disord Drug Targets 2006, 6:69-83.

5. Lopez-Ribot JL, McAtee RK, Lee LN, Kirkpatrick WR, White TC, Sanglard D, Patterson TF: Distinct patterns of gene expression associated with development of fluconazole resistance in serial Candida albicans isolates from human immunodeficiency virus-infected patients with oropharyngeal candidiasis. Antimicrob Agents Chemother 1998, 42:2932-2937.

6. Harry JB, Song JL, Lyons CN, White TC: Transcription initiation of genes associated with azole resistance in Candida albicans. Med Mycol 2002, 40:73-8I.

7. Prasad R, De WP, Goffeau A, Balzi E: Molecular cloning and characterization of a novel gene of Candida albicans, CDRI, conferring multiple resistance to drugs and antifungals. Curr Genet 1995, 27:320-329.

8. Sanglard D, Kuchler K, Ischer F, Pagani JL, Monod M, Bille J: Mechanisms of resistance to azole antifungal agents in Candida albicans isolates from AIDS patients involve specific multidrug transporters. Antimicrob Agents Chemother 1995, 39:2378-2386.

9. White TC: Increased mRNA levels of ERG I6, CDR, and MDRI correlate with increases in azole resistance in Candida albicans isolates from a patient infected with human immunodeficiency virus. Antimicrob Agents Chemother 1997, 41: 1482-I487.

10. Gaur M, Choudhury D, Prasad R: Complete inventory of ABC proteins in human pathogenic yeast, Candida albicans. J Mol Microbiol Biotechnol 2005, 9:3-15.

II. Pao SS, Paulsen IT, Saier MH Jr: Major facilitator superfamily. Microbiol Mol Biol Rev 1998, 62: I-34.

12. Paulsen IT, Sliwinski MK, Nelissen B, Goffeau A, Saier MH Jr: Unified inventory of established and putative transporters encoded within the complete genome of Saccharomyces cerevisiae. FEBS Lett 1998, 430:116-125.

13. Saier $\mathrm{MH}$ Jr: A functional-phylogenetic system for the classification of transport proteins. J Cell Biochem 1999:84-94.

14. Saier MH Jr: Molecular phylogeny as a basis for the classification of transport proteins from bacteria, archaea and eukarya. Adv Microb Physiol 1998, 40:81-136.

15. Busch W, Saier MH Jr: The transporter classification (TC) system, 2002. Crit Rev Biochem Mol Biol 2002, 37:287-337.

16. Alvarez FJ, Konopka JB: Identification of an $\mathbf{N}$-acetylglucosamine transporter that mediates hyphal induction in Candida albicans. Mol Biol Cell 2007, 18:965-975.

17. Calabrese D, Bille J, Sanglard D: A novel multidrug efflux transporter gene of the major facilitator superfamily from Candida albicans (FLUI) conferring resistance to fluconazole. Microbiology 2000, I 46(Pt I I):2743-2754.

18. Hu CJ, Bai C, Zheng XD, Wang YM, Wang Y: Characterization and functional analysis of the siderophore-iron transporter CaArnlp in Candida albicans. I Biol Chem 2002, 277:30598-30605.

19. Pasrija R, Banerjee D, Prasad R: Structure and function analysis of CaMdr Ip, a major facilitator superfamily antifungal efflux transporter protein of Candida albicans: identification of amino acid residues critical for drug/ $/ \mathbf{H}+$ transport. Eukaryot Cell 2007, 6:443-453

20. Kohli A, Gupta V, Krishnamurthy S, Hasnain SE, Prasad R: Specificity of drug transport mediated by CaMDRI: a major facilitator of Candida albicans. J Biosci 200I, 26:333-339.

21. Sengupta M, Datta A: Two membrane proteins located in the Nag regulon of Candida albicans confer multidrug resistance. Biochem Biophys Res Commun 2003, 30 I: 1099-I 08. 
22. Soares-Silva I, Paiva S, Kotter P, Entian KD, Casal M: The disruption of JENI from Candida albicans impairs the transport of lactate. Mol Membr Biol 2004, 2 I:403-4II.

23. Fan J, Chaturvedi V, Shen $\mathrm{SH}$ : Identification and phylogenetic analysis of a glucose transporter gene family from the human pathogenic yeast Candida albicans. J Mol Evol 2002, 55:336-346.

24. Ben-Yaacov R, Knoller S, Caldwell GA, Becker JM, Koltin Y: Candida albicans gene encoding resistance to benomyl and methotrexate is a multidrug resistance gene. Antimicrob Agents Chemother 1994, 38:648-652.

25. Fling ME, Kopf J, Tamarkin A, Gorman JA, Smith HA, Koltin Y: Analysis of a Candida albicans gene that encodes a novel mechanism for resistance to benomyl and methotrexate. Mol Gen Genet |99|, 227:318-329.

26. Becker JM, Henry LK, Jiang W, Koltin Y: Reduced virulence of Candida albicans mutants affected in multidrug resistance. Infect Immun 1995, 63:45I5-45 I8.

27. Gupta V, Kohli A, Krishnamurthy S, Puri N, Aalamgeer SA, Panwar S, Prasad R: Identification of polymorphic mutant alleles of CaMDRI, a major facilitator of Candida albicans which confers multidrug resistance, and its in vitro transcriptional activation. Curr Genet 1998, 34: 192-199.

28. Braun BR, van Het Hoog M, d'Enfert C, Martchenko M, Dungan J, Kuo A, Inglis DO, Uhl MA, Hogues H, Berriman M, Lorenz M, Levitin A Oberholzer U, Bachewich C, Harcus D, Marcil A, Dignard D, louk T, Zito R, Frangeul L, Tekaia F, Rutherford K, Wang E, Munro CA, Bates S, Gow NA, Hoyer LL, Kohler G, Morschhauser J, Newport G, Znaid S, Raymond M, Turcotte B, Sherlock G, Costanzo M, Ihmels J, Berman J, Sanglard D, Agabian N, Mitchell AP, Johnson AD, Whiteway M, Nantel A: A human-curated annotation of the Candida albicans genome. PLoS Genet 2005, I:36-57.

29. Varma A, Singh BB, Karnani N, Lichtenberg-Frate H, Hofer M, Magee $\mathrm{BB}$, Prasad R: Molecular cloning and functional characterisation of a glucose transporter, CaHGTI, of Candida albicans. FEMS Microbiol Lett 2000, I 82: I5-2I.

30. Palma M, Goffeau A, Spencer-Martins I, Baret PV: A phylogenetic analysis of the sugar porters in hemiascomycetous yeasts. J Mol Microbiol Biotechnol 2007, I 2:24 I-248.

31. Goldway M, Teff D, Schmidt R, Oppenheim AB, Koltin Y: Multidrug resistance in Candida albicans: disruption of the BENr gene. Antimicrob Agents Chemother 1995, 39:422-426.

32. Gompel-Klein P, Brendel M: Allelism of SNQI and ATRI, genes of the yeast Saccharomyces cerevisiae required for controlling sensitivity to 4-nitroquinoline- $\mathbf{N}$-oxide and aminotriazole. Curr Genet 1990, 18:93-96.

33. Kanazawa S, Driscoll M, Struhl K: ATRI, a Saccharomyces cerevisiae gene encoding a transmembrane protein required for aminotriazole resistance. Mol Cell Biol 1988, 8:664-673.

34. Ehrenhofer-Murray AE, Wurgler FE, Sengstag C: The Saccharomyces cerevisiae SGEI gene product: a novel drug-resistance protein within the major facilitator superfamily. Mol Gen Genet 1994, 244:287-294.

35. Amakasu H, Suzuki Y, Nishizawa M, Fukasawa T: Isolation and characterization of SGEI: a yeast gene that partially suppresses the gal I I mutation in multiple copies. Genetics 1993 I 34:675-683.

36. Goffeau A, Park J, Paulsen IT, Jonniaux JL, Dinh T, Mordant P, Saier $\mathrm{MH}$ Jr: Multidrug-resistant transport proteins in yeast: complete inventory and phylogenetic characterization of yeast open reading frames with the major facilitator superfamily. Yeast 1997, 13:43-54.

37. Namy O, Duchateau-Nguyen G, Hatin I, Hermann-Le DS, Termier M, Rousset JP: Identification of stop codon readthrough genes in Saccharomyces cerevisiae. Nucleic Acids Res 2003, 3 I :2289-2296.

38. Bun-Ya M, Nishimura M, Harashima S, Oshima Y: The PHO84 gene of Saccharomyces cerevisiae encodes an inorganic phosphate transporter. Mol Cell Biol I99I, I I:3229-3238.

39. Harrison MJ, van Buuren ML: A phosphate transporter from the mycorrhizal fungus Glomus versiforme. Nature 1995 , 378:626-629.

40. Abe K, Ruan ZS, Maloney PC: Cloning, sequencing, and expression in Escherichia coli of OxIT, the oxalate:formate exchange protein of Oxalobacter formigenes. J Biol Chem 1996, 271:6789-6793.
4I. Anantharam V, Allison MJ, Maloney PC: Oxalate:formate exchange. The basis for energy coupling in Oxalobacter. J Biol Chem 1989, 264:7244-7250.

42. Fu D, Maloney PC: Evaluation of secondary structure of OxIT, the oxalate transporter of Oxalobacter formigenes, by circular dichroism spectroscopy. J Biol Chem 1997, 272:2129-2I 35.

43. Ruan ZS, Anantharam V, Crawford IT, Ambudkar SV, Rhee SY, Allison $\mathrm{MJ}$, Maloney $\mathrm{PC}$ : Identification, purification, and reconstitution of OxIT, the oxalate: formate antiport protein of Oxalobacter formigenes. J Biol Chem 1992, 267: I0537-10543.

44. Lodi T, Diffels J, Goffeau A, Baret PV: Evolution of the carboxylate Jen transporters in fungi. FEMS Yeast Res 2007, 7:646-656.

45. Makuc J, Paiva S, Schauen M, Kramer R, Andre B, Casal M, Leao C, Boles E: The putative monocarboxylate permeases of the yeast Saccharomyces cerevisiae do not transport monocarboxylic acids across the plasma membrane. Yeast 200I, I 8: | | 3 | - | | 43 .

46. Yun CW, Ferea T, Rashford J, Ardon O, Brown PO, Botstein D, Kaplan J, Philpott CC: Desferrioxamine-mediated iron uptake in Saccharomyces cerevisiae. Evidence for two pathways of iron uptake. J Biol Chem 2000, 275:10709-107I5.

47. Heymann P, Gerads M, Schaller M, Dromer F, Winkelmann G, Ernst JF: The siderophore iron transporter of Candida albicans (Sitlp/ArnIp) mediates uptake of ferrichrome-type siderophores and is required for epithelial invasion. Infect Immun 2002, 70:5246-5255.

48. Grundemann D, Gorboulev V, Gambaryan S, Veyhl M, Koepsell H: Drug excretion mediated by a new prototype of polyspecific transporter. Nature 1994, 372:549-552.

49. Urakami Y, Okuda M, Masuda S, Saito H, Inui KI: Functional characteristics and membrane localization of rat multispecific organic cation transporters, OCTI and OCT2, mediating tubular secretion of cationic drugs. J Pharmacol Exp Ther 1998 , 287:800-805.

50. Kekuda R, Prasad PD, Wu X, Wang H, Fei YJ, Leibach FH, Ganapathy $\mathrm{V}$ : Cloning and functional characterization of a potential-sensitive, polyspecific organic cation transporter (OCT3) most abundantly expressed in placenta. I Biol Chem 1998, 273:|597|-|5979.

5I. Koepsell H, Busch A, Gorboulev V, Arndt P: Structure and Function of Renal Organic Cation Transporters. News Physiol Sci 1998, I3:11-16.

52. Bindra PS, Knowles R, Buckley KM: Conservation of the amino acid sequence of SV2, a transmembrane transporter in synaptic vesicles and endocrine cells. Gene 1993, I 37:299-302.

53. Bajjalieh SM, Peterson K, Shinghal R, Scheller RH: SV2, a brain synaptic vesicle protein homologous to bacterial transporters. Science 1992, 257:1271-1273.

54. Gingrich JA, Andersen PH, Tiberi M, el MS, Jorgensen PN, Fremeau RT Jr, Caron MG: Identification, characterization, and molecular cloning of a novel transporter-like protein localized to the central nervous system. FEBS Lett 1992, 3 I 2: I I 5- I 22.

55. Janz R, Hofmann K, Sudhof TC: SVOP, an evolutionarily conserved synaptic vesicle protein, suggests novel transport functions of synaptic vesicles. J Neurosci 1998, I 8:9269-928I.

56. Kanamori A, Nakayama J, Fukuda MN, Stallcup WB, Sasaki K, Fukuda $M$, Hirabayashi $Y$ : Expression cloning and characterization of a cDNA encoding a novel membrane protein required for the formation of O-acetylated ganglioside: a putative acetylCoA transporter. Proc Natl Acad Sci USA 1997, 94:2897-2902.

57. Lindquist S, Weston-Hafer K, Schmidt H, Pul C, Korfmann G, Erickson J, Sanders C, Martin HH, Normark S: AmpG, a signal transducer in chromosomal beta-lactamase induction. Mol Microbiol I 993, 9:703-7I5.

58. Shayeghi M, Latunde-Dada GO, Oakhill JS, Laftah AH, Takeuchi K, Halliday N, Khan Y, Warley A, McCann FE, Hider RC, Frazer DM, Anderson G], Vulpe CD, Simpson RJ, McKie AT: Identification of an intestinal heme transporter. Cell 2005, I 22:789-80I.

59. Latunde-Dada GO, Takeuchi K, Simpson RJ, McKie AT: Haem carrier protein I ( $\mathrm{HCPI})$ : Expression and functional studies in cultured cells. FEBS Lett 2006, 580:6865-6870.

60. Altschul SF, Madden TL, Schaffer AA, Zhang J, Zhang Z, Miller W, Lipman D): Gapped BLAST and PSI-BLAST: a new generation of protein database search programs. Nucleic Acids Res 1997, 25:3389-3402. 
61. Hulo N, Bairoch A, Bulliard V, Cerutti L, De CE, LangendijkGenevaux PS, Pagni M, Sigrist CJ: The PROSITE database. Nucleic Acids Res 2006, 34:D227-D230.

62. Mulder NJ, Apweiler R: The InterPro database and tools for protein domain analysis. Curr Protoc Bioinformatics 2008, Chapter 2:.

63. Marchler-Bauer A, Anderson JB, Cherukuri PF, Weese-Scott C, Geer LY, Gwadz M, He S, Hurwitz DI, Jackson JD, Ke Z, Lanczycki CJ, Liebert CA, Liu C, Lu F, Marchler GH, Mullokandov M, Shoemaker BA, Simonyan V, Song JS, Thiessen PA, Yamashita RA, Yin JJ, Zhang D, Bryant SH: CDD: a Conserved Domain Database for protein classification. Nucleic Acids Res 2005, 33:DI92-DI 96.

64. Saier MH Jr, Tran CV, Barabote RD: TCDB: the Transporter Classification Database for membrane transport protein analyses and information. Nucleic Acids Res 2006, 34:DI8I-DI 86.

65. Gerads M, Ernst JF: Overlapping coding regions and trancriptional units of two essential chromosomal genes (CCT8, TRPI) in the fungal pathogen Candida albicans. Nucleic Acids Res 1998, 26:506I-5066.

66. Xu D, Jiang B, Ketela T, Lemieux S, Veillette K, Martel N, Davison J, Sillaots S, Trosok S, Bachewich C, Bussey H, Youngman P, Roemer T: Genome-wide fitness test and mechanism-of-action studies of inhibitory compounds in Candida albicans. PLoS Pathog 2007, 3:e92.

67. Lepak A, Nett J, Lincoln L, Marchillo K, Andes D: Time course of microbiologic outcome and gene expression in Candida albicans during and following in vitro and in vivo exposure to fluconazole. Antimicrob Agents Chemother 2006, 50:131I-1319.

68. Bennett RJ, Johnson AD: The role of nutrient regulation and the $\mathrm{Gpa2}$ protein in the mating pheromone response of $C$. albicans. Mol Microbiol 2006, 62:100-119.

69. Liu TT, Lee RE, Barker KS, Lee RE, Wei L, Homayouni R, Rogers PD: Genome-wide expression profiling of the response to azole, polyene, echinocandin, and pyrimidine antifungal agents in Candida albicans. Antimicrob Agents Chemother 2005, 49:2226-2236.

70. Bensen ES, Martin SJ, Li M, Berman J, Davis DA: Transcriptional profiling in Candida albicans reveals new adaptive responses to extracellular pH and functions for Rim IO I p. Mol Microbiol 2004, 54:|335-|35|.

71. Hromatka BS, Noble SM, Johnson AD: Transcriptional response of Candida albicans to nitric oxide and the role of the YHBI gene in nitrosative stress and virulence. Mol Biol Cell 2005 16:48|4-4826.
Publish with Biomed Central and every scientist can read your work free of charge

"BioMed Central will be the most significant development for disseminating the results of biomedical research in our lifetime. "

Sir Paul Nurse, Cancer Research UK

Your research papers will be:

- available free of charge to the entire biomedical community

- peer reviewed and published immediately upon acceptance

- cited in PubMed and archived on PubMed Central

- yours - you keep the copyright
BioMedcentral 